\title{
Overweight and Obesity among Adults Aged 18-45 Years Residing in and around Giyani Town in Mopani District of Limpopo Province, South Africa
}

\author{
Motadi SA ${ }^{* 1}$, Veldsman $\mathrm{T}^{2}$, Mohlala $\mathrm{M}^{2}$ and Mabapa $\mathrm{NS}^{1}$ \\ ${ }^{1}$ Nutrition Department, School of Health Sciences, University of Venda, Thohoyandou, South Africa \\ ${ }^{2}$ Center for Biokinetics, Recreation and Sports Science, School of Health Sciences University of Venda, Thohoyandou, \\ South Africa
}

${ }^{*}$ Corresponding author: Motadi SA, Nutrition Department, School of Health Sciences, University of Venda, Private bag x5050, Thohoyandou, Limpopo province, 0950, South Africa, Tel: +27159628683, E-mail: selekane.motadi@univen.ac.za

Citation: Motadi SA, Veldsman T, Mohlala M, Mabapa NS (2017) Overweight and Obesity among Adults Aged 18-45 Years Residing in and around Giyani Town in Mopani District of Limpopo Province, South Africa. J Nutr Health Sci 5(1): 102. doi: 10.15744/2393-9060.5.102

Received Date: August 27, 2017 Accepted Date: February 06, 2018 Published Date: February 09, 2018

\begin{abstract}
Objective: To describe the prevalence of overweight and obesity among adults aged 18-45 years residing in and around Giyani town.

Methods: This study included 100 participants recruited from a location in Greater Giyani Municipality of Mopani district, Limpopo Province, South Africa. This Municipality was purposively selected and convenience sampling was used to choose study participants. Body weight and height were measured using standard techniques. Waist circumference, systolic, diastolic, glucose, cholesterol and body fat levels were also assessed.

Results: The prevalence of overweight and obesity was $18.1 \%$ and $20.5 \%$, respectively. Obesity was more prevalent in females (19\%) than males (1.5\%). The risks found in study participants included hypertension, diabetes, high total cholesterol, alcohol consumption and cigarette smoking. There was a significant difference in systolic blood pressure $(p \leq 0.03)$ between males and females.Systolic blood pressure of about $22.9 \%$ of male participants compared to females (20\%) was in the hypertensive range.However, only $9.2 \%$ of females had prehypertension of between $85-89 \mathrm{mmHg}$. Furthermore, $17.1 \%$ of males had hypertension values $\geq 90 \mathrm{mmHg}$ as compared to $9.2 \%$ of their female counterparts.

Conclusion: Overweight and obesity were common in adults residing in urban areas. The results observed here call for intervention to combat the rising problem of overweight and obesity among adults in the form of nutrition education to ensure food diversification and reduction of food containing fats and hidden fats.
\end{abstract}

Keywords: Overweight; Obesity; Body mass index; Body fat; Waist circumference; Total cholesterol

\section{Introduction}

Historically, obesity and overweight were considered problems of affluent countries, but and is increasingly affecting developing countries like South Africa [1]. In South Africa, obesity is fundamentally driven by environmental changes such as urbanisation, accompanied by cultural modernisation which promotes the adoption of an unhealthy lifestyle plus unhealthy eating habits and decreased physical activity [2]. Furthermore, South Africa has become a market liberalised country in which many people in rural areas access fast food due to market globalisation that leads to a change in dietary patterns and reduced levels of exercise [3].

In many rural communities around South Africa, obesity and overweight are still associated with a sign of good health as well as affluence, today this perception has drastically changed on the basis of evidence that obesity and overweight are associated with a wide range of serious health complications and increased risk of non-communicable diseases (NCDs), such as cardiovascular disease, type 2 diabetes, hypertension and high serum triglycerides which are leading causes of death [4-8]. The unhealthy situation of high levels of physical inactivity and obesity provides a basis for non-communicable disease, also known as "chronic diseases of lifestyle" [9].

In South Africa the burden of NCDs has increased over the past 15 years causing an estimated 37\% of mortalities and $16 \%$ of disability-adjusted life years [10]. According to Miranda et al. non-communicable diseases (NCDs) are the leading causes of 
morbidity and mortality in most in low and middle-income countries [11]. These diseases mostly result from behaviours such as tobacco use, physical inactivity, unhealthy diet, and the harmful use of alcohol that lead to four key metabolic/physiological changes such as raised blood pressure, overweight/obesity, raised blood glucose and raised cholesterol [12].

South Africa, like any other developing country, is undergoing a rapid transition with increased intake of energy dense foods and decreased level of physical activity due to increasing urbanisation, changing modes of transportation and sedentary working environments [13-15]. In several developing countries, obesity has established itself as a public health concern with many communities having higher prevalence, particularly among those of higher socioeconomic status [4,16-18]. The highest rate of overweight and obesity among adults in sub-Saharan Africa is found in South African women (42\%), while the combined rate of both overweight and obesity is 69.3\% [19]. Guthold et al. in their survey on low- and middle-income countries, reported that South Africa was ranked as the country with the third prevalence of physical inactivity [20]. In view of this, this study was conducted to evaluate prevalence of obesity and overweight among adults in and around Giyani in Mopani district of Limpopo Province, South Africa.

\section{Methodology}

\section{Study Population}

The study was conducted in Mopani District, which is one of five municipal districts of Limpopo Province. Mopani district's economy is predominately rural-based and the district was selected due to its vast development of modern shopping centres with all the well-known chain stores presented which could lead to lifestyle changes. Lifestyle changes have a very important impact on shopping behavior. During the student placement at this district, the community profiling revealed that majority of rural adults visiting the health centres this district were overweight and obese. The district is divided into six local municipalities, namely Ba-Phalaborwa, Greater Giyani, Greater Letaba, Greater Tzaneen and Maruleng. Convenience sampling was used to select one Greater Giyani Municipality. Greater Giyani had an estimated population of 244217. Giyani town is divided into five sections, namely section A, D1, D2, E, F and Kremataart [21]. Giyani is a north-eastern town in the Limpopo Province, South Africa and a former capital of the then Gazankulu bantustan. Giyani is situated at the intersection between the R578 road (South Africa) and the R81. It is located in the heart of Limpopo Bushveld, on the northern bank of the Klein (Little) Letaba River west of Kruger National Park. Convenience sampling was used to select one hundred (100) participants. The study was conducted at AM Fitness centre in the heart of Giyani town in the Limpopo Province of South Africa. Data was collected during a three days' period by a team of health professionals (a nurse, a nutritionist and a biokineticists) in October 2015. Participants were aged between 18 and 45 years, consented and were present on the day of data collection. Participants who were in wheelchairs were excluded due to the lack of equipment to measure their weight and height. The questionnaire used to determine health status and health practices was adopted from the Belloc and Breslow [22]. Eating habits were determined using closed questions regarding consumption and frequency of fast foods. Fast were considered to be take away purchased from fast foods restaurants. An expert from the Department of Linguistics at the University of Venda translated the questionnaire into the local language used in Giyani which is Xitsonga. Anthropometric assessments were performed according to standard procedures as described by the International Society for the Advancement of Kinanthropometry. The following measurements were taken in duplicate using calibrated equipment with the adult wearing light clothing and no shoes: standing height and weight. Height was measured to the nearest $0.1 \mathrm{~cm}$ using a calibrated portable stadiometer and weight was measured to the nearest $0.01 \mathrm{~kg}$ on a portable Seca solar scale (model 0213) (Seca, Hammer Steindamm, Hamburg, Germany). The solar scale and stadiometer were calibrated before measurements using a calibration weight and steel tape respectively [23].

\section{Biochemical Analysis}

Resting blood pressure (OMRON, Intelli-sense M6 comfort, Japan) was measured with a validated OMRON M6 Comfort device after the participants had been seated for ten minutes. Two resting measurements, five minutes apart, were performed. The participants were seated upright and relaxed, the right arm supported at heart level. The blood pressure, glucose and cholesterol were taken by a professional nurse. The glucose (random) and cholesterol concentrations were determined by means of peripheral blood sampling (Cardiochek ${ }^{\circledast}$ PA, Indiana).Total body fat was determined using Tanita innerScan V (model BC-601, Japan) by a Biokineticists.

\section{Definition of Overweight, Obesity, Diabetes, Hypertension, Hyperlipidaemia and Body Fat Percentages}

Overweight was defined as $25-29.5 \mathrm{~kg} / \mathrm{m}^{2}$ and obesity was defined as BMI $>30 \mathrm{~kg} / \mathrm{m}^{2}$ [23]. A glucose level between $6.0-6.9 \mathrm{mmol} / \mathrm{L}$ was considered as moderate while glucose level of $>7 \mathrm{mmol}$ was considered high (diabetic range) [24]. Hypertensive range was defined as Systolic blood pressure of $140 \mathrm{mmHg}$ and Diastolic blood pressure of $>90 \mathrm{mmHg}$ while systolic blood pressure of $130=139 \mathrm{mmHg}$ and Diastolic blood pressure of $85-89 \mathrm{mmHg}$ was considered as prehypertensive range [25]. Hyperlipidaemia was defined as total cholesterol of $>7 \mathrm{mmol} / \mathrm{L}$ while $5.2-7 \mathrm{mmol} / \mathrm{L}$ was considered borderline high [24].Total body fat of 15-20\% for males and 24-30\% for females was considered ideal/optimal while 16-29\% was considered as slightly overfat [26].

\section{Ethical Considerations}

Ethical clearance was obtained from the University of Venda Research Ethics Committee and the study was approved by the 
Provincial Department of Health Research Committee. The study was performed in accordance with the principles of the Declaration of Helsinki (2008), Good Clinical Practices and the laws of South Africa. An oral and written explanation of the study, including possible risks, was provided to the participants. Participants gave signed consent before they could participate in the study.

\section{Statistical Analysis}

The data was exported into Statistical Package for Social Sciences (IBM SPSS Statistics., Armonk, NY) version 23 for further analysis along with the biochemical measurements. Descriptive statistics were computed on the data and the mean and standard deviation were used to describe continuous data while frequencies were used to describe categorical data. Spearman's correlation coefficients were computed to compare relationships between anthropometric measurements and biochemical measures. For comparison of gender, the Independent t-tests were used. A $p \leq 0.01$ and $p \leq 0.05$ were considered statistically significant.

\section{Results}

Table 1 provides the socio-demographic characteristics of males and females.About $27.7 \%$ of females were married compared to $25.7 \%$ of males. Furthermore, $85.7 \%$ of males had tertiary education compared to $84.6 \%$ of females. The majority (50.8\%) of females worked 8 hours/day compared to $34.3 \%$ of their male counterparts.

\begin{tabular}{|c|c|c|}
\hline & $\begin{array}{c}\text { Males } \\
(n=35) \%\end{array}$ & $\begin{array}{c}\text { Females } \\
(n=65) \%\end{array}$ \\
\hline \multicolumn{3}{|c|}{ Marital status } \\
\hline Married & $9(25.7)$ & $18(27.7)$ \\
\hline Divorced & $2(5.7)$ & $2(3.1)$ \\
\hline Widowed & $0(0)$ & $5(7.7)$ \\
\hline Cohabiting & $0(0)$ & $1(1.5)$ \\
\hline Single & $23(65.7)$ & $38(58.5)$ \\
\hline Missing value & $1(2.9)$ & $1(1.5)$ \\
\hline \multicolumn{3}{|c|}{ Educational level } \\
\hline $\begin{array}{c}\text { Never attended } \\
\text { school }\end{array}$ & $0(0)$ & $0(0)$ \\
\hline Primary education & $1(2.9)$ & $1(1.5)$ \\
\hline Secondary education & $4(11.4)$ & $6(9.2)$ \\
\hline Tertiary education & $30(85.7)$ & $55(84.6)$ \\
\hline Other & $0(0)$ & $2(3.1)$ \\
\hline Missing value & $0(0)$ & $1(1.5)$ \\
\hline \multicolumn{3}{|c|}{ Occupation } \\
\hline Cleaner & $0(0)$ & $2(3.1)$ \\
\hline Clerk & $2(5.7)$ & $6(9.2)$ \\
\hline Typist & $0(0)$ & $1(1.5)$ \\
\hline Secretary & $0(0)$ & $7(10.8)$ \\
\hline Artisan & $2(5.7)$ & $0(0)$ \\
\hline Security guard & $3(8.6)$ & $4(6.2)$ \\
\hline Student & $23(65.7)$ & $24(36.9)$ \\
\hline Other & $5(14.3)$ & $21(32.3)$ \\
\hline \multicolumn{3}{|c|}{ Work/study hours } \\
\hline 6 hours/day & $12(34.3)$ & $17(26.2)$ \\
\hline 7 hours/day & $3(8.6)$ & $4(6.2)$ \\
\hline 8 hours/day & $12(34.3)$ & $33(50.8)$ \\
\hline$>8$ hours & $4(11.4)$ & $7(10.8)$ \\
\hline Other & $2(5.7)$ & $2(3.1)$ \\
\hline Missing value & $2(5.7)$ & $2(3.1)$ \\
\hline
\end{tabular}

Table 1: Demographic characteristics of male and female participants

The prevalence of overweight and obesity was $18.1 \%$ and $20.5 \%$, respectively. Obesity was more prevalent in females (19\%) than males (1.5\%), although not statistically significant. About $9.5 \%$ of males were overweight compared to $8.6 \%$ of females $(\mathrm{P} \leq 0.01)$ (Table 2). 


\begin{tabular}{|c|c|c|c|c|}
\hline BMI category & $\begin{array}{c}\text { Male (n=35) } \\
\mathbf{n}(\%)\end{array}$ & $\begin{array}{c}\text { Female }(\mathbf{n}=\mathbf{6 5} \\
\mathbf{n}(\%)\end{array}$ & $\begin{array}{c}\text { Total }(\mathbf{n}=\mathbf{1 0 0}) \\
\mathbf{n}(\%)\end{array}$ & P-value \\
\hline Normal BMI & $21(16)$ & $30(24)$ & $51(40.2)$ & 0.02 \\
\hline Overweight BMI 25-29.5 & $12(9.5)$ & $11(8.6)$ & $23(18.1)$ & 0.0 \\
\hline Obese BMI>30 & $2(1.5)$ & $24(19)$ & $26(20.5)$ & 0.28 \\
\hline
\end{tabular}

BMI: Body Mass Index

The level of significance is set at: $\mathrm{p} \leq 0.01$ and $\mathrm{p} \leq 0.05$.

Table 2: Prevalence of obesity and overweight between male and female participants

The mean age was $30.37 y$ in males and $33.97 y$ in females. There was a significant difference in SBP ( $\mathrm{p} \leq 0.03$ ) between males and females. There was no significant difference in non-fasting glucose level between males and females (Table 3 ).

\begin{tabular}{|c|c|c|c|}
\hline Variables & Males & Females & P \\
\hline Age (years) & $30.37 \pm 13.83$ & $33.97 \pm 12.13$ & 0.20 \\
\hline SBP (mmHg) & $132.36 \pm 26.42$ & $121.16 \pm 19.04$ & $\mathbf{0 . 0 3}$ \\
\hline DBP (mmHg) & $76.26 \pm 16.57$ & $73.99 \pm 11.21$ & 0.47 \\
\hline Glucose (mmol/L) & $6.42 \pm 4.34$ & $6.01 \pm 2.60$ & 0.61 \\
\hline Cholesterol (mmol/L) & $4.24 \pm 1.32$ & $4.18 \pm 1.27$ & 0.84 \\
\hline Body fat $(\%)$ & $23.55 \pm 13.35$ & $36.55 \pm 6.95$ & - \\
\hline $\begin{array}{c}\text { Waist } \\
\text { circumference }(\mathbf{c m})\end{array}$ & $81.14 \pm 14.13$ & $87.94 \pm 16.55$ & - \\
\hline
\end{tabular}

SBP $=$ Systolic Blood Pressure; DBP = Diastolic Blood Pressure; BMI = Body Mass Index; $\mathrm{SD}=$ Standard Deviation

The level of significance is set at: $\mathrm{p} \leq 0.05$.

Table 3: Results of the clinical characteristics and comparison thereof between male

and female participants

In the total population, BMI was positively correlated with SBP $(r=\mathbf{0 . 3 2} ; \mathrm{p}=\mathbf{0 . 0 0 1})$ and $\mathrm{DBP}(\mathrm{r}=\mathbf{0 . 3 9} ; \mathrm{p}=\mathbf{0 . 0 0 0})$. Furthermore, $\mathrm{BMI}$ was also positively correlated with blood glucose level $(\mathrm{r}=\mathbf{0 . 3 1} ; \mathrm{p}=\mathbf{0 . 0 0 1})$ and total body fat $(\mathrm{r}=\mathbf{0 . 6 2 2} ; \mathrm{p}=\mathbf{0 . 0 0 0})$. In addition, BMI was positively correlated with total cholesterol $(\mathrm{r}=\mathbf{0 . 1 9} ; \mathrm{p}=\mathbf{0 . 0 5})$ and waist circumference $(\mathrm{r}=\mathbf{0 . 7 8} ; \mathrm{p}=\mathbf{0 . 0 0 0})$. Waist circumference was positively correlated with SBP $(r=0.43 ; p=0.000)$, DBP $(r=0.48 ; p=0.000)$, blood glucose level $(r=0.25 ; p=0.01)$, total body fat $(\mathrm{r}=\mathbf{0 . 5 2} ; \mathrm{p}=\mathbf{0 . 0 0 0})$ and total cholesterol $(\mathrm{r}=\mathbf{0 . 1 2} ; \mathrm{p}=\mathbf{0 . 2 0})($ Table 4$)$.

\begin{tabular}{|c|c|c|c|c|c|c|c|c|}
\hline & & Systolic & Diastolic & Blood sugar & Body fat & Cholesterol & BMI & Waist \\
\hline \multirow{2}{*}{ BMI } & $\mathrm{r}$ & $\mathbf{0 . 3 2}$ & 0.39 & $\mathbf{0 . 3 1}$ & 0.622 & $\mathbf{0 . 1 9}$ & - & 0.78 \\
\cline { 2 - 9 } & $\mathrm{p}$ & $\mathbf{0 . 0 0 1}$ & 0.000 & $\mathbf{0 . 0 0 1}$ & 0.000 & $\mathbf{0 . 0 5}$ & & 0.000 \\
\hline \multirow{2}{*}{ WC } & $\mathrm{r}$ & 0.43 & 0.48 & $\mathbf{0 . 2 5}$ & 0.52 & 0.12 & 0.78 & - \\
\cline { 2 - 9 } & $\mathrm{p}$ & 0.000 & 0.000 & $\mathbf{0 . 0 1}$ & 0.000 & 0.20 & 0.000 & \\
\hline
\end{tabular}

BMI: Body Mass Index; WC = waist circumference

The level of significance is set at: $\mathrm{p} \leq 0.05$. and $\mathrm{p}<0.01$

Table 4: Correlation between Anthropometric measurements (BMI and Waist) and biochemical variable

In males, $\mathrm{BMI}$ was positively correlated with $\mathrm{SBP}(\mathrm{r}=\mathbf{0 . 4 5} ; \mathrm{p}=0.006), \mathrm{DBP}(\mathrm{r}=\mathbf{0 . 3 5} ; \mathrm{p}=\mathbf{0 . 0 3})$, blood glucose level $(\mathrm{r}=\mathbf{0 . 6 4} ; \mathrm{p}=\mathbf{0 . 0 0 0})$ body fat $(\mathrm{r}=\mathbf{0 . 5 3} ; \mathrm{p}=\mathbf{0 . 0 0 1})$, total cholesterol $(\mathrm{r}=\mathbf{0 . 1 7} ; \mathrm{p}=\mathbf{0 . 3 2})$ and waist circumference $(\mathrm{r}=\mathbf{0 . 7 9} ; \mathrm{p}=\mathbf{0 . 0 0 0})$. Waist circumference was positively correlated with SBP $(r=0.47 ; p=0.004)$, DBP $(r=0.42 ; p=0.01)$ and blood glucose level $(r=0.35 ; p=0.03)$.

\begin{tabular}{|c|c|c|c|c|c|c|c|c|}
\hline & & Systolic & Diastolic & Blood sugar & Body fat & Cholesterol & BMI & Waist \\
\hline \multicolumn{9}{|c|}{ Males } \\
\hline \multirow{2}{*}{ BMI } & $\mathrm{r}$ & 0.45 & 0.35 & 0.64 & 0.53 & 0.17 & - & 0.79 \\
\hline & $\mathrm{p}$ & 0.006 & 0.03 & 0.000 & 0.001 & 0.32 & & 0.000 \\
\hline \multirow{2}{*}{$\begin{array}{c}\text { WAIST } \\
\text { CIRCUMFERENCE }\end{array}$} & $\mathrm{r}$ & 0.47 & 0.42 & 0.35 & 0.44 & -0.04 & 0.79 & - \\
\hline & $\mathrm{p}$ & 0.004 & 0.01 & 0.03 & 0.007 & 0.78 & 0.000 & \\
\hline \multicolumn{9}{|c|}{ Females } \\
\hline \multirow{2}{*}{ BMI } & $\mathrm{r}$ & 0.45 & 0.53 & 0.23 & 0.73 & 0.22 & - & 0.77 \\
\hline & $\mathrm{p}$ & 0.000 & 0.000 & 0.05 & 0.000 & 0.07 & & 0.000 \\
\hline \multirow{2}{*}{$\begin{array}{c}\text { WAIST } \\
\text { CIRCUMFERENCE }\end{array}$} & $\mathrm{r}$ & 0.56 & 0.60 & 0.23 & 0.62 & 0.22 & 0.77 & \\
\hline & $\mathrm{p}$ & 0.000 & 0.000 & 0.05 & 0.000 & 0.07 & 0.000 & \\
\hline
\end{tabular}

BMI: Body Mass Index

The level of significance is set at: $\mathrm{p} \leq 0.05$. and $\mathrm{p}<0.01$

Table 5: Correction between anthropometric measurements and biochemical variable in male 
In females, BMI was positively correlated with SBP $(\mathrm{r}=\mathbf{0 . 4 5} ; \mathrm{p}=\mathbf{0 . 0 0 6}), \mathrm{DBP}(\mathrm{r}=\mathbf{0 . 3 5} ; \mathrm{p}=\mathbf{0 . 0 0 0})$, blood glucose level ( $\mathrm{r}=\mathbf{0 . 2 3}$; $\mathrm{p}=0.05)$, total body fat $(\mathrm{r}=\mathbf{0 . 7 3} ; \mathrm{p}=\mathbf{0 . 0 0 0})$, total cholesterol $(\mathrm{r}=\mathbf{0 . 2 2} ; \mathrm{p}=\mathbf{0 . 0 7})$ and waist circumference $(\mathrm{r}=\mathbf{0 . 7 9} ; \mathrm{p}=\mathbf{0 . 0 0 0})$. Waist circumference was positively correlated with SBP $(r=0.56 ; p=0.000), D B P(r=0.60 ; p=0.000)$, blood glucose level $(r=0.23 ; p=0.05)$, total body fat $(\mathrm{r}=\mathbf{0 . 6 2} ; \mathrm{p}=\mathbf{0 . 0 0 0})$ and total cholesterol $(\mathrm{r}=\mathbf{0 . 2 2} ; \mathrm{p}=\mathbf{0 . 0 7})$ (Table 5).

About $20 \%$ of males purchased fast food everyday compared to $7.7 \%$ of females.In addition, only $23.1 \%$ of females purchased fast food once a week compared to $20 \%$ of their male counterparts. About $28.6 \%$ of males preferred to purchase KFC while $40 \%$ of females purchased fish and chips (Table 6).

\begin{tabular}{|c|c|c|}
\hline \multicolumn{3}{|c|}{ Frequency of purchasing fast food } \\
\hline & $\begin{array}{l}\text { Males } \\
\text { n (\%) }\end{array}$ & $\begin{array}{c}\text { Females } \\
\text { n (\%) }\end{array}$ \\
\hline Everyday & $7(20)$ & $5(7.7)$ \\
\hline Once a week & $7(20)$ & $15(23.1)$ \\
\hline Twice a week & $5(14.3)$ & $3(4.6)$ \\
\hline 3 times a week & $4(11.4)$ & $7(10.8)$ \\
\hline Once a month & $4(11.4)$ & $12(18.5)$ \\
\hline Twice a month & $4(11.4)$ & $10(15.4)$ \\
\hline $\begin{array}{c}\text { More than twice } \\
\text { a month }\end{array}$ & $4(11.4)$ & $8(12.3)$ \\
\hline \multicolumn{3}{|c|}{ Fast food usually purchased } \\
\hline Romans & $3(8.6)$ & $5(7.7)$ \\
\hline Chicken Licken & $2(5.7)$ & $2(3.1)$ \\
\hline KFC & $10(28.6)$ & $2(3.1)$ \\
\hline Fish and chips & $5(14.3)$ & $26(40)$ \\
\hline Nando's & $8(22.9)$ & $2(3.1)$ \\
\hline Galito's & $3(8.6)$ & $15(23.1)$ \\
\hline Chisa nyama & $1(2.9)$ & $6(9.2)$ \\
\hline
\end{tabular}

Table 7 provides the distribution of non-communicable disease risk factors between males and females. About $22.9 \%$ of males had SBP in the hypertensive range compared to $20 \%$ of females.In addition, only $17.1 \%$ of males had higher than normal DBP in the hypertensive range compared to $9.2 \%$ of females. About $17.1 \%$ of males had blood glucose level higher than $7 \mathrm{mmol} / \mathrm{L}$ compared to $20 \%$ of their female counterparts. Males (17.1\%) had moderate total cholesterol compared to $15.4 \%$ of females.About $95.4 \%$ of females had high total body fat compared to $45.7 \%$ of males. At total of $46.1 \%$ of females were alcohol drinkers compared to $37.1 \%$ of males. In addition, $11.4 \%$ of males were smokers compared to $3.1 \%$ of females.

\begin{tabular}{|c|c|c|}
\hline Variables & $\begin{array}{c}\text { Males } \\
(n=35) \%\end{array}$ & $\begin{array}{l}\text { Females } \\
(n=65) \%\end{array}$ \\
\hline \multicolumn{3}{|c|}{ SBP (mmHg) } \\
\hline Normal (120-129) & $22(62.9)$ & $40(70.8)$ \\
\hline Prehypertension (130-139) & $5(14.3)$ & $6(9.2)$ \\
\hline Hypertension $(\geq 140)$ & $8(22.9)$ & $13(20)$ \\
\hline \multicolumn{3}{|c|}{ DBP (mmHg) } \\
\hline Normal (80-84) & $29(82.9)$ & $53(81.5)$ \\
\hline Prehypertension (85-89) & $0(0)$ & $6(9.2)$ \\
\hline Hypertension $(\geq 90)$ & $6(17.1)$ & $6(9.2)$ \\
\hline \multicolumn{3}{|c|}{ Glucose $(\mathrm{mmol} / \mathrm{L})$} \\
\hline Low (5.5-5.9) & $21(60)$ & $40(61.5)$ \\
\hline Moderate (6.0-6.9) & $8(22.9)$ & $12(18.5)$ \\
\hline High $(>7)$ & $6(17.1)$ & $13(20)$ \\
\hline \multicolumn{3}{|c|}{ T-Cholesterol (mmol/L) } \\
\hline Low $(<5.2)$ & $28(80)$ & $54(83.1)$ \\
\hline Moderate (5.2-7.5) & $6(17.1)$ & $10(15.4)$ \\
\hline $\operatorname{High}(>7)$ & $1(2.9)$ & $1(1.5)$ \\
\hline
\end{tabular}




\begin{tabular}{|c|c|c|}
\hline Variables & $\begin{array}{c}\text { Males } \\
(\mathrm{n}=35) \%\end{array}$ & $\begin{array}{l}\text { Females } \\
(n=65) \%\end{array}$ \\
\hline \multicolumn{3}{|c|}{ Body fat (\%) } \\
\hline Lean $(<8)$ & $11(31.4)$ & $3(4.6)$ \\
\hline $\begin{array}{l}\text { Optimal (males 15-20; } \\
\text { females 24-30) }\end{array}$ & $8(22.9)$ & $0(0)$ \\
\hline $\begin{array}{l}\text { Overweight (16-29 males; } \\
\text { females } 31-36)\end{array}$ & $16(45.7)$ & $62(95.4)$ \\
\hline \multicolumn{3}{|c|}{ BMI $\left(\mathrm{kg} / \mathrm{m}^{2}\right)$} \\
\hline Normal (18.5-24.0) & $21(60)$ & $30(46.2)$ \\
\hline Overweight (25-25.9) & $12(34.3)$ & $11(16.9)$ \\
\hline Obese $(>30)$ & $2(5.7)$ & $24(36.9)$ \\
\hline \multicolumn{3}{|c|}{ Waist circumference $(\mathrm{cm})$} \\
\hline Low (male 94; female 80 ) & $28(80)$ & $21(32.3)$ \\
\hline $\begin{array}{l}\text { High (male } 94-102 \text {; female } \\
\qquad 80-88)\end{array}$ & $5(14.3)$ & $13(20)$ \\
\hline $\begin{array}{l}\text { Very high }(\text { male }>102 ; \\
\text { female }>88)\end{array}$ & $2(5.7)$ & $31(47.7)$ \\
\hline \multicolumn{3}{|c|}{ Smoking status } \\
\hline Non-smokers & $31(88.6)$ & $59(90.8)$ \\
\hline Smokers & $4(11.4)$ & $2(3.1)$ \\
\hline \multicolumn{3}{|c|}{ Alcohol consumption } \\
\hline Non-drinkers & $22(62.9)$ & $32(49.2)$ \\
\hline Drinkers & $13(37.1)$ & $30(46.1)$ \\
\hline \multicolumn{3}{|c|}{ PA status } \\
\hline $\mathrm{PA}$ & $22(62.9))$ & $23(35.4)$ \\
\hline PIA & $13(37.1)$ & $42(64.6)$ \\
\hline
\end{tabular}

SBP = Systolic Blood pressure; DBP = Diastolic Blood Pressure; T-Cholesterol = Total Cholesterol; $\mathrm{BMI}=$ Body Mass Index; PA = Physical activity; PIA = Physical inactivity.

Table 7: Risk factors in male and female participants residing in and around Giyani town $\mathrm{n}(\%)$

\section{Discussion}

The aim of the study was to determine the prevalence of overweight and obesity among adults aged 18-45 years residing in and around Giyani town in Mopani District of Limpopo Province, South Africa. The results of the study revealed that the prevalence of overweight and obesity was $18.1 \%$ and $20.5 \%$ respectively. The results are higher than the provincial prevalence of $4.8 \%$ (overweight) and 3.3\% (obesity). The results also showed that the prevalence of overweight and obesity was higher in females than in males (8.6\% and 19\% for females as compared with $9.5 \%$ and $1.5 \%$ of males, respectively). The prevalence of overweight and obesity in the current study was lower than the national prevalence of overweight and obesity in females and males $(25 \%$ and $40.1 \%$ compared with $19.6 \%$ and $11.6 \%$ for females and males, respectively) [2]. However, the prevalence was lower when looking at provinces with Limpopo having $24 \%$ and $32.6 \%$ compared with $16.3 \%$ and $11.5 \%$ for females and males, respectively [2].

The high prevalence of overweight and obesity in the current study may be explained by the fact that more males are eating fast food daily and weekly combined (40\%) while still have a low percentage of overweight /obesity compared to females. The consumption of fast food may be enhanced by meals that cost less than R50 in various fast food outlets which the public regards as cheap and convenient. Increased consumption of fast food meals every day coupled with a lack of physical activity can lead to increased calories resulting in weight gain and other health conditions. The environment in South Africa has obviously changed during the last decades, whereas opportunities to eat energy-dense foods are omnipresent [27]. Today, fast food restaurants that sell greasy burgers, chips and sugary drinks are found at most intersections in every town around Limpopo Province. This fast food outlets make it hard for people to plan their meals ahead and work or even shop because of the availability and accessibility. Egger and Swinburn suggested that the increasing obesogenic environment is the driving force for the increasing prevalence of obesity rather than any 'pathology' in metabolic defects or genetic mutations within individuals [28]. Additional factors that could explain the high rates of overweight and obesity in South Africa include changes in nutritional patterns over time and the degree of urbanisation that Africans are undergoing [29]. Overweight and obesity in adults increase the risk of debilitating health problems such as type 2 diabetes, hypertension, high serum triglycerides and cardiovascular disease which are leading causes of death [7].

South Africa has one of the highest levels of alcohol consumption in the world [30-32]. In this study, females (46.1\%) were found to be more frequent alcohol drinkers than males (37.1\%). Surprisingly, the SANHANES report Shisana et al. divulged 
that males (31\%) were more prone to drinking than females (9.3\%) [2]. Alcohol may have a negative impact on the health of an individual. Although alcohol is high in kilojoules $(28 \mathrm{~kJ} / \mathrm{g})$, it is not metabolised as efficiently as carbohydrates and fats and is deficient in essential micronutrients [33]. Impaired digestion may result in malabsorption of vitamins thiamine, B12, folic acid, zinc and amino acids. Furthermore, metabolism is also altered and certain nutrients are frequently affected (thiamine, vitamin B6, vitamin D, zinc, vitamin A, magnesium, phosphorus and selenium) [34]. Nevertheless, consuming alcohol with meals may have some protective factors to overindulgence and this may in turn reduce intoxication [35-38]. Excessive alcohol intake may be contributing significantly to energy intake and may eventually facilitate weight gain in participants [39].

Another possible cause of overweight and obesity is physical inactivity. Physical inactivity among the female participants was particularly high and this could be one of the possible reason for this alarming high rate of overweight and obesity in the female participants. Congruently, WHO revealed that $42.2 \%$ of males and $51.6 \%$ of females in South Africa are physically inactive [40]. In South Africa, overweight and obesity in women is perceived as a sign of good health as well as affluence, happiness and prosperity $[4,8,41]$. This was also confirmed in a study done by Faber and Kruger in rural villages of KwaZulu-Natal, where females who were obese did not perceive themselves as being too big or overweight [41]. Being an overweight and obese female in an African community has many positive connotations [4].

This study showed that the majority (50.8\%) of females spend 8 hours per day working/studying compared to $34.3 \%$ of their male counterparts. This could be the leading cause of physical inactivity among the study participants, as most participants have little time for physical activity. According to Milia and Mummery and Kim et al. long working hours can lead to poor sleeping habits and less time for exercise and maintaining a balanced diet which are strongly linked to obesity and increased risk for cardiovascular diseases [42,43]. Furthermore, several studies have reported an association between long working hours and obesity in several countries, including Hong Kong, Australia and Finland [43-45]. At the same time, Micklesfield et al. reported that the prevalence of physical activity in South Africa is estimated to be between 43-49\% among adolescents and adults [46]. Lifestyle changes generated by technology and capitalism have affected the way we exercise and eat, leading to a risk of diseases [47].

Results show that females had higher body fat percentages compared to their male counterparts, exceeding the recommended optimal body fat of 31-36\% [48]. Perhaps the scientific explanations for females having a higher fat percentage may also be due to differences in hormones, hormone receptors and enzyme concentrations [49]. Concurrently, Whitney and Rolfes reported that fat accumulation is higher in females than in males, due to essential body fat deposited in the mammary glands and pelvic region in preparation for child bearing [50]. Another factor that might contribute to females having a higher fat percentage than their male counterparts, may be the use of hormonal contraceptives [51].The high prevalence of overweight and obesity indicated by BMI values and the fat percentage of the female participants is in line with the high prevalence of waist circumferences above the normal values of $88 \mathrm{~cm}$ for women. Only a small portion of the male participants had a greater than $102 \mathrm{~cm}$ waist circumference [48].

University or college is known to be a critical period for making unhealthy changes in eating behaviours and weight gain [5255]. This study showed that the majority (65.7\%) of males were students compared to $36.9 \%$ of females. According to Deliens et al. when students fail to adapt adequately to the new environment, this could have negative consequences towards their health behaviour and subsequent weight status [55]. Eating behaviour is an important factor influencing students' weight [53]. However, dietary changes have been observed in South African adults from low fat diets to typical westernised high fat diets [56]. South Africa has become a market liberalised country in which many people in rural areas access fast food due to market globalisation which leads to change in dietary patterns and reduced levels of exercise [3].

This study showed that females (47.7\%) had a very high central obesity compared to $5.7 \%$ of their male counterparts. Perhaps this could be attributed to the fact that the hormones oestrogens and androgens help to regulate body fat distribution. Furthermore, postmenopausal women tend to increase storage of fat around their abdomen because the distribution of fat in the body changes after middle age [57-59]. Therefore, with the increase in age, the risk of overweight and obesity increases gradually.

About $17.1 \%$ of males were at risk of hypertension compared to $9.2 \%$ of females, when using DBP, while $22.9 \%$ of males were at risk of hypertension compared to $20 \%$ of females, when using SBP. This could be explained by the fact that $11.4 \%$ of males were smokers compared to $3.1 \%$ of females. Smoking cigarettes acutely exerts a hypertensive effect, mainly through the stimulation of the sympathetic nervous system [60].The association between BMI and metabolic diseases among adults was further explored in this study. The results indicated that hypertension, diabetes and hyperlipidemia had a positive association with BMI and WC, which is consistent with previous studies [61,62]. One possible explanation for this is that BMI is very highly correlated with WC. The risk of metabolic diseases can be more accurately predicted by WC after adjustment for the influence of BMI. The results further showed that people with BMI above normal and very high WC have a higher risk of metabolic diseases.

\section{Conclusion and Recommendation}

A high prevalence of both overweight and obesity exists among adults in urban areas of Giyani. The prevalence of overweight and obesity in the current study was lower than nationally and provincially. Hypertension, diabetes and hyperlipidemia were significantly associated with BMI and WC among adults in Giyani, Mopani district. The high prevalence could be a result of 
dietary changes that have been observed in South Africa, from low fat diets to typical westernised high fat diets and market liberalisation which makes people access fast food due to market globalisation which leads to a change in dietary patterns. The high prevalence of obesity among females compared to their male counterparts could be a result of South African overweight and obesity in women being associated with a sign of good health as well as affluence, happiness and prosperity. Nutrition education programs on the consequences of overweight and obesity and the consumption of fast foods should include the importance of dietary diversification of meals, especially the inclusion of fruits and vegetables and the reduction of food that contain high fat content and hidden fats. Physical activity should be introduced at school level as this is known to prevent overweight and obesity which delays manifestation of non-communicable disease. Furthermore, Government and health departments should take measures to improve people's awareness of the consequences of overweight and obesity.

\section{Acknowledgements}

The authors would like to acknowledge the University of Venda and students from the Department of Nutrition, Biokineticists, Nursing Sciences and Psychology for assisting with data collection. Furthermore, we would like to pass our message of appreciation to participants residing in and around Giyani town for their participation and cooperation.

\section{References}

1. Cois A, Day C (2015) Obesity trends and risk factors in the South African adult population. BMC Obes 2: 42.

2. Shisana O, Labadarios D, Rehle T, Simbayi L, Zuma K, et al. (2013) South African National Health and Nutrition Examination Survey (SANHANES-1). Cape Town, HSRC Press.

3. FAO (2004) Globalization of food systems in developing countries: Impact on food security and nutrition. FAO Food and Nutrition Paper 83, Rome.

4. Mvo Z, Dick J, Steyn K (1999) Perceptions of overweight African women about acceptable body size of women and children. Curationis 22: 27-31.

5. Puoane T, Fourie JM, Shapiro M, Rosling L, Tshaka NC, et al. (2005) "Big is beautiful” - an exploration with urban black community health workers in a South African township. South Afr J Clin Nutr 18: 6-15.

6. Alberti KG, Zimmet P, Shaw J (2006) Metabolic syndrome-a new world-wide definition: a consensus statement from the international diabetes federation. Diabet Med 23: 469-80.

7. Akbartabartartoori M, Lean MEJ, Hankey CR (2008) The associations between current recommendation for physical activity and cardiovascular risk associated with obesity. Eur J Clin Nutr 62: 1-9.

8. Micklesfield LK, Lambert EV, Hume JD, Chantler S, Pienaar PR, et al. (2013) Socio-cultural, environmental and behavioural determinants of obesity in black South African women. Cardiovasc J Afr 24: 369-75.

9. Krisela Steyn, Jean Fourie, Norman Temple (2006) Chronic Diseases of Lifestyle in South Africa: 1995 - 2005. South African Medical Research Council, Cape Town, 1-8.

10. Puoane TR, Tsolekile LP, Caldbick S, Igumbor EI, Meghnath K, et al. (2013) Chronic Non-Communicable Diseases in South Africa: Progress and challenges. SAHR 2012/13.

11. Miranda JJ, Kinra S, Casas JP, Davey Smith G, Ebrahim S (2008) Non-communicable diseases in low- and middle-income countries: context, determinants and health policy. Trop Med Int Health. 13: 1225-34.

12. Saeed KMI (2013) Prevalence of Risk Factors for Non-Communicable Diseases in the Adult Population of Urban Areas in Kabul City, Afghanistan. Cent Asian J Glob Health 2: 2.

13. Bourne L, Lambert EV, Steyn K (2002) Where does the black population of South Africa stand on the nutrition transition? Public Health Nutr 5: 157-62.

14. Bradshaw D, Groenewald P, Laubscher R, Nannan N, Nojilana B, et al. (2003) Initial burden of disease estimates for South Africa, 2000. S Afr Med J 93: 682-8.

15. Pretorius S, Sliwa K (2011) Perspectives and perceptions on the consumption of a healthy diet in Soweto, an urban African community in South Africa. SA Heart J 8: 178-83.

16. Kamadjeu RM, Edwards R, Atanga JS, Kiawi EC, Unwin N, et al. (2006) Anthropometry measures and prevalence of obesity in the urban adult population of Cameroon: an update from the Cameroon Burden of Diabetes Baseline Survey. BMC Public Health 6: 228.

17. Van der Merwe MT, Pepper MS (2006) Obesity in South Africa. Obes Rev 7: 315-22.

18. MacLaren L (2007) Socioeconomic status and obesity. Epidemiologic Reviews 29: 29-48.

19. Ziraba A, Fotso J, Ochako R (2009) Overweight and obesity in urban Africa: a problem of the rich or the poor? BMC Public Health 9: 465.

20. Ng M, Flemming T, Robinson M, Thomson B, Graetz N, et al. (2014) Global, regional, and national prevalence of overweight and obesity in children and adults during 1980-2013: a systematic analysis for the global burden of disease study 2013. Lancet 384: 766-81.

21. Statistics South Africa (STATS SA) (2011) Statistics South Africa. Pretoria, South Africa.

22. Belloc NB, Breslow L (1972) Relationship of physical health status and health practices. Prev Med 1: 409-21.

23. Lee DR, Nieman CD (2010) Nutrition Assessment. $5^{\text {th }}$ Ed. McGraw-Hill Companies, New York.

24. Pathologists Lancet laboratories (2016) Key to diagnostic excellence, South Africa.

25. American College of Sports Medicine (2009) ACSM's guidelines for exercise testing and prescription $8^{\text {th }}$ Ed. Philadelphia Lippincott Williams \& Wilkens.

26. ACE fitness (2017) American Council on Exercise, USA.

27. Guthold R, Ono T, Strong KL, Chatterji S, Marabia A (2008) Worldwide variability in physical inactivity: a 51-country survey. Am J Prev Med 34: 486-94.

28. Egger G, Swinburn B (1997) An "ecological" approach to the obesity pandemic. BMJ 315: 477-80.

29. Puoane T, Steyn K, Bradshaw D, Laubscher R, Fourie J, et al. (2002) Obesity in South Africa: the South African Demographic and health survey. Obes Res 10: 1038-48.

30. World Health Organization (2011) Global status report on alcohol and health. WHO, Geneva, Switzerland. 
31. Steyn NP, Labadarios D, Maunder E, Nel J, Lombard C (2005) Secondary anthropometric data analysis of the National Food Consumption Survey in South Africa: the double burden. Nutrition 21: 4-13.

32. Plüddemann A, Dada S, Parry C (2013) Decline in adolescent treatment admissions for methamphetamine use in Cape Town. South African Med J 103: 478-80.

33. Mahan LK, Escott-Stump S (2008) Krause's Food \& Nutrition Therapy. 12th edition Elsevier Saunders. St Louis Missouri.

34. Jacobs L, Steyn N (2013) Commentary: if you drink alcohol, drink sensibly: is this guideline still appropriate. Ethinicity and disease 23: 110-5.

35. Trevisan M, Ram M, Hovey K, Russell M, Freudenheim J, et al. (2001) Alcohol drinking patterns and myocardial infarction. Am J Epidemiol 153 : S97.

36. Trevisan M, Schisterman E, Mennotti A, Farchi G, Conti S (2001) The risk factor and life expectancy research group drinking pattern and mortality: the Italian risk factor and life expectancy pooling project. Ann Epidemiol 11:312-9.

37. Soul City (2009) Phuza wise: Drink safe, live safe. Gauteng: Soul City Institute.

38. Intoximeters (2013) About alcohol.

39. Brug J, Van Lenthe FJ, Kremers SPJ (2006) Revisiting Kurt Lewin - how to gain insight into environmental correlates of obesogenic behaviors. Am J Pre Med 31: 525-9.

40. WHO (World Health Organization) (2016) Obesity and overweight.

41. Faber M, Kruger S (2005) Dietary intake, perceptions regarding body weight, and attitudes toward weight control or normal weight, overweight, and obese black females in a rural village in South Africa. Ethnicity Disease 15: 238-45.

42. Milia DL, Mummery K (2009) The association between job related factors, short sleep and obesity. Ind Health 47: 363-8.

43. Kim MB, Lee EB, Park SH, Kim YJ, Suh YJ, et al. (2016) Long working hours and overweight and obesity in working adults. Ann Occ Environ Med 28: 36.

44. Ko GT, Chan JC, Chan AW, Wong PT, Hui SS, et al. (2007) Association between sleeping hours, working hours and obesity in Hong Kong Chinese: the 'better health for better Hong Kong 'health promotion campaign. Int J Obes 31: 254-60.

45. Lallukka T, Sarlio-Lahteenkorva S, Kaila-Kangas L, Pitkaniemi J, Luukkonen R, et al. (2008) Working conditions and weight gain: a 28-year follow-up study of industrial employees. Eur J Epidemiol 23: 303-10.

46. Micklesfield L, Pedro T, Kahn K, Kinsman J, Pettifor S, et al. (2014) Physical activity and sedentary behavior among adolescents in rural South Africa: Levels, patterns and correlates. BMC Public Health 14: 40.

47. Lloyd-Richardson EE, Lucero ML, DiBello JR, Jacobson AE, Wing RR (2008) The relationship between alcohol use, eating habits and weight change in college freshmen. Eating Behaviors 9: 504-8.

48. Da Silva Pires CG, Mussi FC, De Cerqueira BB, Pitanga FJG, Da Silva DO (2013) Physical activity practice among undergraduate students in nursing. Acta Paul Enferm 26: 436-43.

49. Vella CA, Kravitz L (2002) Gender differences in fat metabolism. IDEA Health and Fitness Source 20: 36-46.

50. Whitney E, Rolfes SR (2008) Understanding Nutrition. Belmont, CA: Thomson \& Wadsworth.

51. Risser WL, Gefter LR, Barrat MS, Risser JMH (1999) Weight change in adolescents who used hormonal contraception. J Adol Health 24: 433-6.

52. Racette SB, Deusinger SS, Strube MJ, Highstein GR, Deusinger RH (2008) Changes in weight and health behaviours from freshman through senior year of college. J Nutri Educ Behav 40: 39-42.

53. Crombie AP, Ilich JZ, Dutton GR, Panton LB, Abood DA (2009) The freshman weight gain phenomenon revisited. Nutrition Review 67: 83-94.

54. Vella-Zarb RA, Elgar FJ (2009) The 'freshman 5': a meta-analysis of weight gain in the freshman year of college. J Am Coll Health 58: 161-6.

55. Deliens T, Clarys P, De Bourdeaudhuij I, Deforche B (2014) Determinants of eating behaviour in university students: a qualitative study using focus group discussions. BMC Public Health 14: 53.

56. WHO (World Health Organization) (2003) Comparative analysis of food and nutrition policies in WHO European Member States. Full report. Copenhagen, Denmark: WHO Regional Office for Europe.

57. Tchernof A, Despres JP (2013) Pathophysiology of human visceral obesity: an update. Physiol Rev 93: 359-404.

58. Kotani K, Tokunaga K, Fujioka S, Kobatake T, Keno Y, et al. (1994) Sexual dimorphism of age-related changes in whole-body fat distribution in the obese. Int J Obes Rel Metab Disord 18: 207-2.

59. Virdis A, Giannarelli C, Neves MF, Taddei S, Ghiadoni L (2010) Cigarette smoking and hypertension. Curr Pharma Design 16: 2518-25.

60. Su J, Xianq Q, Lyu S, Pan X, Qin Y, et al. (2015) Relationship between central obesity and clustering of cardiovascular risk factors in adults of Jiangsu Province. Zhonghua Xin Xue Guan Bing Za Zhi 43: 548-53.

61. Zhang P, Wang R, Gao C, Jiang L, Lv X, et al. (2016) Prevalence of central obesity among adults with normal BMI and its association with metabolic diseases in Northeast China. PLoS One 11: e0160402.

62. Zhou X, Ji L, Ran X, Su B, Ji Q, et al. (2016) Prevalence of obesity and its influence on achievement of cardiometabolic therapeutic goals in Chinese type 2 diabetes patients: an analysis of the nationwide, cross-sectional 3B study. PloS one 11: e0144179. 


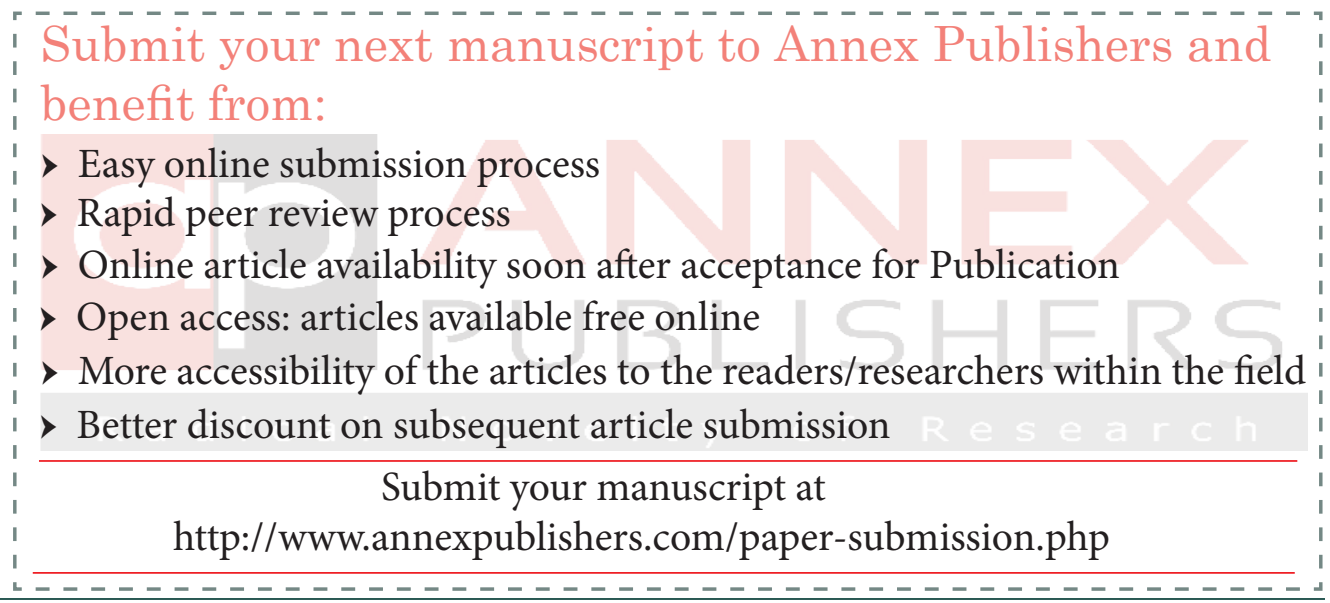

